\title{
X-Ray and Mössbauer Study of Magnetic Black Sand from Mayotte Island
}

\author{
Saverio Braccini ${ }^{*}$, Karl Krämer ${ }^{2}$, Stephane Chapenoire ${ }^{3,4,5}$ \\ ${ }^{1}$ Albert Einstein Center for Fundamental Physics (AEC), Laboratory for High Energy Physics (LHEP), University of Bern, Bern, \\ Switzerland \\ ${ }^{2}$ Department of Chemistry and Biochemistry, University of Bern, Bern, Switzerland \\ ${ }^{3}$ Forensic and Criminal Intelligence Agency of the French Gendarmerie (IRCGN), Cergy-Pontoise, France \\ ${ }^{4}$ Pôle Odontologie et Santé Buccale, CHU Bordeaux, Bordeaux, France \\ ${ }^{5}$ ISPED, Inserm U897, Bordeaux, France \\ Email: *saverio.braccini@lhep.unibe.ch
}

How to cite this paper: Braccini, S., Krämer, K. and Chapenoire, S. (2016) X-Ray and Mössbauer Study of Magnetic Black Sand from Mayotte Island. World Journa of Nuclear Science and Technology, 6, 191198.

http://dx.doi.org/10.4236/wjnst.2016.64020

Received: August 13, 2016

Accepted: September 5, 2016

Published: September 8, 2016

Copyright $\odot 2016$ by authors and Scientific Research Publishing Inc. This work is licensed under the Creative Commons Attribution International License (CC BY 4.0).

http://creativecommons.org/licenses/by/4.0/

(c) (i) Open Access

\begin{abstract}
Natural magnetic black sands are known from several sites often located in areas of volcanic origin. Their elemental and mineral composition provides information on the geology of their territory and depends on several factors occurred during their formation. A sample of black sand was collected on the seashore of the island of Mayotte in the Indian Ocean and its magnetic part was investigated by means of energy dispersive X-ray spectroscopy (EDS), powder X-ray diffraction (XRD), and Mössbauer spectroscopy at room temperature. The mineral composition is dominantly magnetite, in good agreement with samples collected in other sites of volcanic origin. Contrary to pure magnetite, a relevant fraction of Ti was detected by EDS. The 16\% Ti and 1\% Mn content increase the magnetite lattice parameter to 8.4312 (25) A. The broadening of XRD lines pointed towards a significant degree of disorder. This was confirmed by Mössbauer spectroscopy and is attributed to the presence of Ti replacing $\mathrm{Fe}$ in the magnetite lattice. The presence of Ti modifies the local magnetic field on the Fe sites, leading to a broader and more complex Mössbauer transmission spectrum with respect to the one of pure magnetite. To study the effect of temperature, samples were heated for 12 hours to $600^{\circ} \mathrm{C}$ and $800^{\circ} \mathrm{C}$ in argon and to $1000^{\circ} \mathrm{C}$ in air. Annealing in argon did not improve the crystallinity while annealing in air caused a complete decomposition of magnetite into hematite and pseudobrookite.
\end{abstract}

\section{Keywords}

Magnetic Black Sand, Iron Minerals, Energy Dispersive X-Ray Spectroscopy, X-Ray Diffraction, Mössbauer Spectroscopy 


\section{Introduction}

The natural occurrence of strongly magnetic black sands is known from several sites, e.g. in Italy [1], the Black Sea [2], or Costa Rica [3]. Often these sands are of volcanic origin. After erosion of the primary rock, the heavy sands accumulate in alluvial deposits. Due to their high iron oxide content, some deposits attracted interest for mining as iron ore.

The chemical structure of natural samples depends on several factors and conditions occurred during their formation. In particular, the presence of elements different from iron, pressure and time of solidification determine changes in the structure that can be put in evidence and quantitatively studied by means of the experimental methods used in this work.

Due to their high iron content, magnetic black sands are radiopaque and, if present in sufficient quantity, can be detected within biological tissues using radiology based imaging techniques. If ingested or inhaled, magnetic black sands may lead to artifacts in medical imaging techniques (radiography, computed tomography (CT)).

This work originated from a case in forensic medicine. CT imaging revealed the presence of a highly radiopaque object in the trachea of a newborn corpse found on a beach of the isle of Mayotte [4]. The autopsy was performed some days later and showed only the presence of compact black sand in the esophagus and in the trachea. A characterization of this natural material was then performed and allowed demonstrating that compact radiopaque magnetite black sand faked the shape of a metallic weapon. The results of this characterization were found to be interesting beyond this study since the composition of magnetic black sand from Mayotte differs from the one of already published natural samples.

Along the lines of this case in forensic medicine, a sample of magnetic black sand from Mayotte Island was analyzed with the same methodology used in a previous study of black sand from the Mediterranean Sea near Rome [1]. In particular, the mineral and chemical composition were analyzed by energy dispersive X-ray spectroscopy (EDS) [5], powder X-ray diffraction (XRD) [5], and Mössbauer spectroscopy [6]. Radioactivity was assessed via hyper-pure germanium (HPGe) gamma spectroscopy [7].

\section{Materials and Methods}

A sample of natural black sand was collected from a beach situated on the north coast of Mayotte, a French over-sea department situated in the northern Mozambique Channel off the coast of southeast Africa. The sample was separated into a magnetic and a non-magnetic component by means of a strong permanent magnet. The magnetic fraction accounts for about $95 \%$ of the total mass, as reported in Table 1. Only the magnetic fraction was further characterized.

From the separated magnetic component three further samples were prepared. They were heated in a porcelain crucible inside a tubular furnace for 12 hours to $600^{\circ} \mathrm{C}$ and $800^{\circ} \mathrm{C}$ under argon and to $1000^{\circ} \mathrm{C}$ in air.

The elemental composition of the magnetic fraction was analyzed by energy disper- 
sive X-ray spectroscopy using a Noran SIX NSS200 (Thermo Electron Corporation, Madison, WI, USA) detector attached to a Hitachi scanning electron microscope S-3000 N (Hitachi High-Technologies Europe GmbH, Krefeld, Germany).

Powder X-ray diffraction patterns were measured on a Stoe StadiP powder diffractometer (STOE \& Cie. GmbH, Darmstadt, Germany) in reflection geometry (BraggBrentano) at room temperature. $\mathrm{Cu} \mathrm{K}_{\alpha 1}$ radiation $(\lambda=1.540598 \AA)$ was used from a focusing $\alpha$-quartz (101) monochromator. Diffraction patterns were measured from $15^{\circ}$ to $100^{\circ} 2$-Theta with a resolution of $0.01^{\circ}$ using a position sensitive detector. Due to the vast iron content, the samples show a strong absorption of $\mathrm{Cu} \mathrm{K}_{\alpha}$ radiation and concomitant an intense X-ray fluorescence from Fe. The high background due to the X-ray fluorescence was subtracted from the data.

A Mössbauer spectrometer (Fast Com Tec MA-250) equipped with a $5 \mathrm{mCi}^{57} \mathrm{Co}$ source in a $\mathrm{Rh}$ matrix was employed. A proportional tube filled with $97 \% \mathrm{Kr}$ and $3 \%$ $\mathrm{CO}_{2}$ at 1 atm pressure with a thin Be side window (LND 45431) was used to detect the $14.4 \mathrm{keV}$ characteristic Mössbauer line.

\section{Experimental Results}

Three mm-sized black shiny grains belonging to the magnetic component were selected and analyzed by EDS. They turned out to be exactly identical in their composition and are therefore taken as representative for the sample. The elemental composition in atom $\%$ with respect to the metal atoms is reported in Table 2 . The oxygen content is not quantitatively accessible by this method. The sample contains mainly iron with a significant amount of titanium and a small amount of manganese, all in the form of oxide compounds.

Powder X-ray diffraction patterns of the magnetic component and of samples heated under argon to $600^{\circ} \mathrm{C}$ and $800^{\circ} \mathrm{C}$ are shown in Figure 1 . The diffraction pattern of the magnetic fraction, the black trace in Figure 1, corresponds to a cubic magnetite phase

Table 1. Results of the magnetic separation of the sample. The uncertainties are reported in parenthesis.

\begin{tabular}{ccc}
\hline Component & Mass (g) & Fraction (\%) \\
\hline Magnetic & 1.9362 & $95(1)$ \\
Non-magnetic & 0.0979 & $5(1)$ \\
Total & 2.0341 & 100 \\
\hline
\end{tabular}

Table 2. EDS analysis of the magnetic fraction. The uncertainties are reported in parenthesis.

\begin{tabular}{cc}
\hline Element & Atom (\%) \\
\hline $\mathrm{Fe}$ & $82.8(4)$ \\
$\mathrm{Ti}$ & $16.2(3)$ \\
$\mathrm{Mn}$ & $1.0(3)$ \\
\hline
\end{tabular}




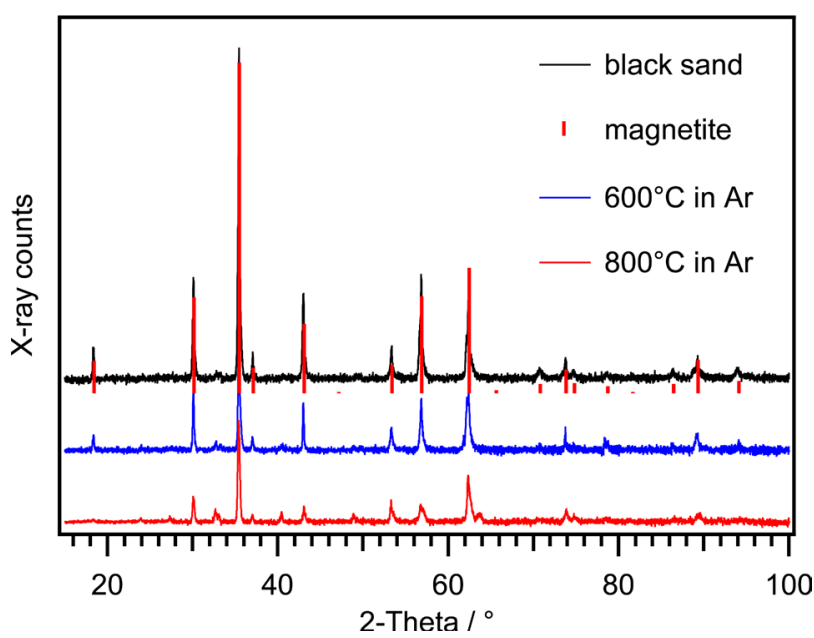

Figure 1. Powder X-ray diffraction patterns of the magnetic fraction (black line) and under argon gas thermally processed samples at $600^{\circ} \mathrm{C}$ (blue line) and $800^{\circ} \mathrm{C}$ (red line). The Bragg peak positions and intensities of magnetite are shown as reference (red ticks). Patterns were measured with $\mathrm{Cu} \mathrm{K}_{\alpha 1}$ radiation $(\lambda=1.540598 \AA)$ at room temperature.

with space group Fd-3m. A calculated pattern is shown as red ticks below the black trace. The positions and the intensities of the Bragg peaks agree very well between measured and calculated patterns. Only a minor peak around $33^{\circ} 2$-Theta does not belong to the magnetite phase.

The cubic lattice parameter was refined with the STOE WinXPow diffractometer software as $a=8.4312(25) \AA$. It is slightly bigger than for pure magnetite $\mathrm{Fe}_{3} \mathrm{O}_{4}$ for which a typical parameter value of $a=8.3930$ (6) Å was found in literature [8].

The increase of the lattice parameter is due to the significant Ti content of the sample. $\mathrm{Ti}^{4+}$ replaces $\mathrm{Fe}^{3+}$ on the tetrahedral site of the spinel lattice. The ionic radii are $0.42 \AA$ for $\mathrm{Ti}^{4+}$ and $0.49 \AA$ for $\mathrm{Fe}^{3+}$ for four-fold coordination $(\mathrm{CN}=4)$ [9]. Due to the different valence of $\mathrm{Ti}^{4+}$ vs. $\mathrm{Fe}^{3+}$ charge compensation is required. It can be achieved in various ways, e.g., by replacing an octahedral $\mathrm{Fe}^{3+}$ by $\mathrm{Fe}^{2+}$. The respective ionic radii for $\mathrm{CN}=6$ are $0.645 \AA$ for high spin (HS) $\mathrm{Fe}^{3+}$ and $0.78 \AA$ for $\mathrm{HS} \mathrm{Fe}^{2+}$. Accordingly, the replacement of $\mathrm{Fe}^{3+}(\mathrm{CN}=4)$ and $\mathrm{Fe}^{3+}(\mathrm{HS}, \mathrm{CN}=6)$ by $\mathrm{Ti}^{4+}$ and $\mathrm{Fe}^{2+}(\mathrm{HS}, \mathrm{CN}=6)$ results in a lattice expansion. Another realistic mechanism for the charge compensation of the $\mathrm{Ti}^{4+} / \mathrm{Fe}^{3+}$ substitution is the creation of cation defects.

The diffraction pattern shows rather broad peaks, which indicate a significant degree of disorder in the magnetite phase. Above about $50^{\circ}$ 2-Theta, the peaks show indications for splitting which may be due to lattice distortions towards lower symmetry.

It was attempted to improve the crystallinity of the material by heating the sample in argon to $600^{\circ} \mathrm{C}$ and $800^{\circ} \mathrm{C}$. The corresponding diffraction patterns are shown in Figure 1 as blue and red traces, respectively. The crystallinity was not improved by heating. Rather in contrast, a partial decomposition is observed. Additional weak Bragg peaks occur, especially for the sample heated to $800^{\circ} \mathrm{C}$. They are due to the formation of hematite $\mathrm{Fe}_{2} \mathrm{O}_{3}$ (space group R-3c) [9] and pseudobrookite $\mathrm{Fe}_{2} \mathrm{TiO}_{5}$ (space group Ccmm) [10] [11]. The pattern of the sample heated to $1000^{\circ} \mathrm{C}$ in air is reported in Figure 2. It 
shows a complete decomposition of the magnetite phase into hematite and pseudobrookite. The decomposition is driven by the oxidation of $\mathrm{Fe}$ (II) to $\mathrm{Fe}$ (III) in air and the separation of $\mathrm{Ti}$ from the magnetite into the $\mathrm{Fe}_{2} \mathrm{TiO}_{5}$ phase.

Mössbauer spectroscopy was performed at room temperature on the natural sample as well as on the samples obtained after annealing at $600^{\circ} \mathrm{C}$ and $800^{\circ} \mathrm{C}$ in $\mathrm{Ar}$, and at $1000^{\circ} \mathrm{C}$ in air. More than $10^{6}$ events per channel were collected for all spectra in order to reduce the statistical uncertainty at a level of less then $10^{-3}$ on each channel. The spectra were compared to the one obtained by analyzing the magnetic part of a black sand sample collected from the seashore of Ladispoli in Italy [1], see Figure 3.

The spectrum in Figure 3 can be interpreted as almost pure magnetite with iron in both tetrahedral and octahedral sites and can be fitted by two sextets, as reported in

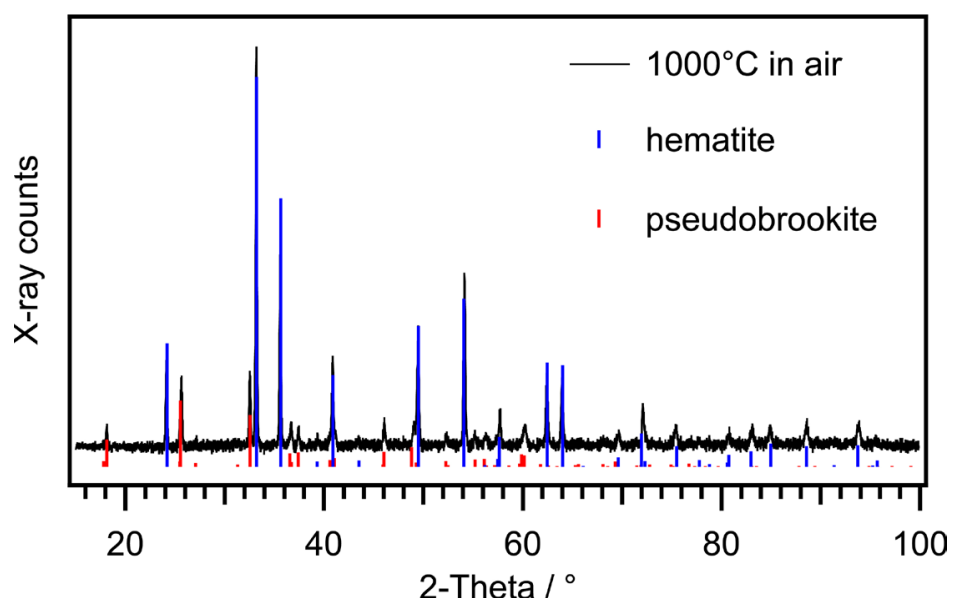

Figure 2. Powder X-ray diffraction pattern of a sample heated in air to $1000^{\circ} \mathrm{C}$. The pattern changed completely from magnetite to hematite and pseudobrookite. The pattern was measured with $\mathrm{Cu} \mathrm{K}_{\alpha 1}$ radiation $(\lambda=1.540598 \AA)$ at room temperature.

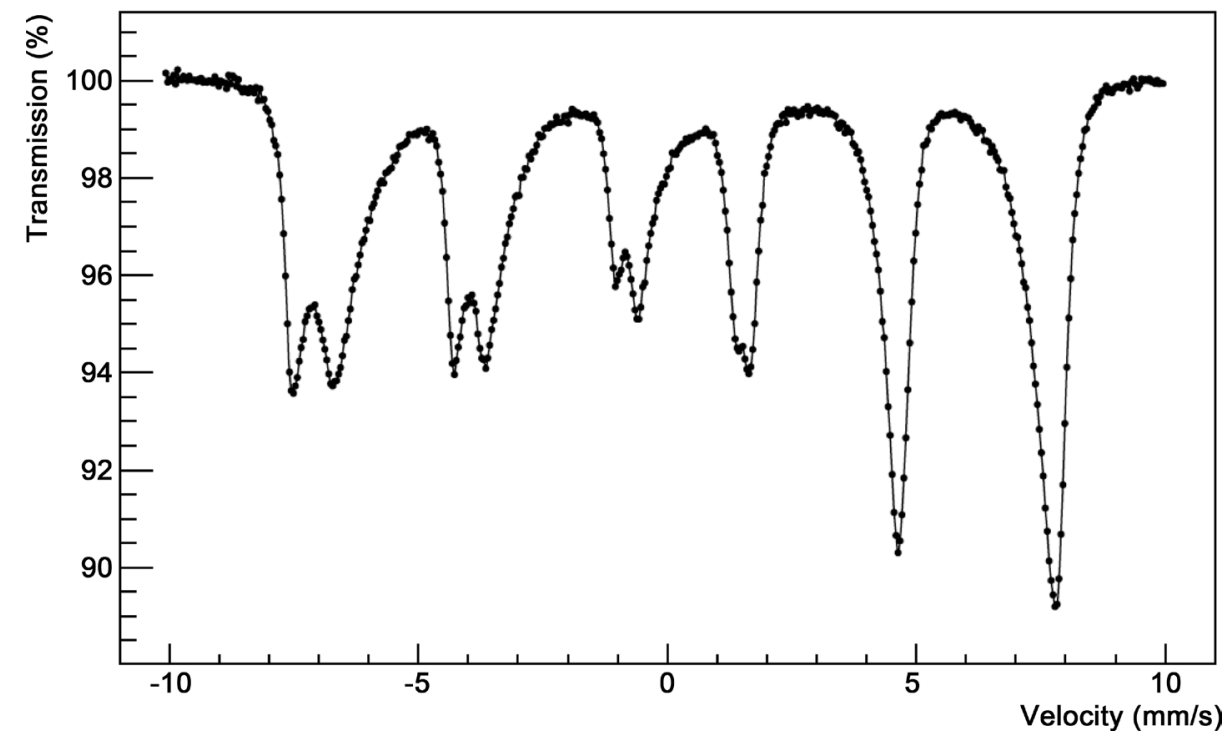

Figure 3. Mössbauer transmission spectrum of magnetic separated black sand from Ladispoli (Italy) corresponding to almost pure magnetite with iron in both tetrahedral and octahedral sites. 
Table 3. For the isomeric shift (IS) the data are referred to $\alpha$-Fe taken as zero. These results are in agreement with literature [1], where only a non-magnetically separated sample was analyzed by Mössbauer spectroscopy. The transmission spectra obtained with the sample from Mayotte island are reported in Figure 4.

The natural sample presents a complex spectrum with enhancements that correspond to the characteristic peaks of magnetite with iron in both tetrahedral and octahedral sites, as reported in literature [1] and in agreement with Figure 3 and Table 3. Contrary to the black sand from Ladispoli, the sample from Mayotte indicates a significant disorder in the magnetite phase in agreement with powder X-ray diffraction

Table 3. Mössbauer parameters of the fit performed on the transmission spectrum obtained with the magnetic separated sample of sand from Ladispoli (Italy).

\begin{tabular}{cccccccc}
\hline \multirow{2}{*}{$\chi^{2} / \mathrm{ndf}$} & Function & HF & QS & IS & Area & AR & \multirow{2}{*}{ AS } \\
\cline { 3 - 7 } & & {$[\mathrm{T}]$} & {$[\mathrm{mm} / \mathrm{s}]$} & {$[\mathrm{mm} / \mathrm{s}]$} & {$[\% \mathrm{~mm} / \mathrm{s}]$} & {$[\%]$} & \\
\hline \multirow{2}{*}{2.0} & Sextet 1 & 47.59 & -0.02 & 0.28 & 16.0 & 30.4 & Mag.A \\
& Sextet 1 & 44.14 & -0.05 & 0.60 & 36.5 & 69.6 & Mag.B \\
\hline
\end{tabular}

HF: hyperfine splitting magnetic field, QS: quadrupole splitting, IS: isomeric shift, AR: area ratio, AS: assignment, Mag. A: magnetite with iron on tetrahedral sites, Mag. B: magnetite with iron on octahedral sites.

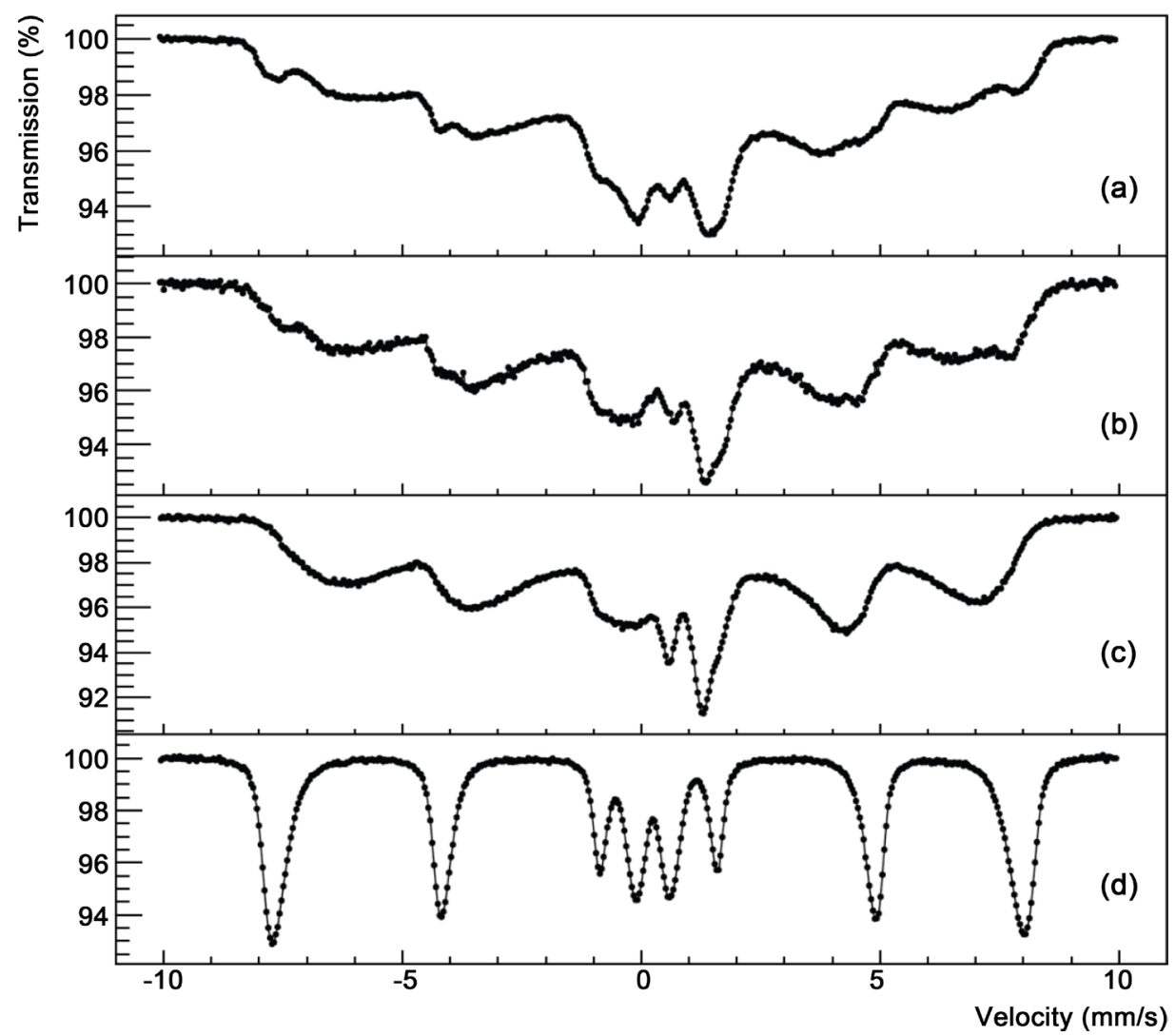

Figure 4. Mössbauer transmission spectra of magnetic separated black sand from Mayotte island: natural sample (a); after 12 hour annealing in $\mathrm{Ar}$ at $600^{\circ} \mathrm{C}$ (b) and at $800^{\circ} \mathrm{C}(\mathrm{c})$; after 12 hour annealing at $1000^{\circ} \mathrm{C}(\mathrm{d})$ in air. 
Table 4. Mössbauer parameters of the fit performed on the transmission spectrum obtained with the magnetic separated sample of sand from Mayotte heated at $1000^{\circ} \mathrm{C}$ in air.

\begin{tabular}{cccccccc}
\hline \multirow{2}{*}{$\chi^{2} / \mathrm{ndf}$} & Function & HF & QS & IS & Area & AR & \multirow{2}{*}{ AS } \\
\cline { 3 - 7 } & & {$[\mathrm{T}]$} & {$[\mathrm{mm} / \mathrm{s}]$} & {$[\mathrm{mm} / \mathrm{s}]$} & {$[\% \mathrm{~mm} / \mathrm{s}]$} & {$[\%]$} & \\
\hline \multirow{2}{*}{5.2} & Sextet & 48.60 & -0.21 & 0.36 & 22.8 & 78.6 & Hematite \\
& Doublet & & 0.61 & 0.35 & 6.24 & 21.4 & Pseudobrookite \\
\hline
\end{tabular}

HF: hyperfine splitting magnetic field, QS: quadrupole splitting, IS: isomeric shift, AR: area ratio, AS: assignment.

results. This disorder affects the magnetic field on the iron sites, determining strong broadening effects in the spectrum. Annealing at $600^{\circ} \mathrm{C}$ and $800^{\circ} \mathrm{C}$ in $\mathrm{Ar}$ slightly improve the sharpness of the enhancements. Although the position of the enhancements correspond to magnetite, a fit of the transmission spectrum is not feasible.

As observed with powder X-ray diffraction, the sample heated to $1000^{\circ} \mathrm{C}$ in air is completely transformed into hematite and pseudobrookite without any magnetite left over. The corresponding Mössbauer transmission spectrum (Figure 4(d)) also changes completely and can be fitted with one sextet and one doublet, compatible with hematite and pseudobrookite values reported in literature [12]. The results of the fit are reported in Table 4.

Traces of radioactive elements were searched for on a sample of non-magnetically separated sand by HPGe gamma spectroscopy. Naturally occurring radionuclides of terrestrial origin coming from the ${ }^{226} \mathrm{Ra}(115 \pm 13 \mathrm{~Bq} / \mathrm{kg})$ and ${ }^{232} \mathrm{Th}(7 \pm 5 \mathrm{~Bq} / \mathrm{kg})$ decay chains were found to be compatible with average natural radioactivity reported in literature [13].

\section{Conclusion}

A sample of magnetic black sand from the island of Mayotte was studied by means of EDS, XRD, and Mössbauer spectroscopy. Magnetite was found as main component, in good agreement with similar samples collected in other sites of volcanic origin. Contrary to pure magnetite, a relevant fraction of Ti was measured by EDS. Ti increases the lattice parameter of the magnetite phase. Furthermore, a significant degree of disorder in the magnetite phase was found by XRD. This was confirmed by Mössbauer spectroscopy, which showed a much broader transmission spectrum with respect to the typical magnetite pattern composed by two sextets. These effects are mostly due to $\mathrm{Ti}$ replacing $\mathrm{Fe}$ in the crystal lattice. In particular, the presence of Ti modifies the local magnetic field on the Fe sites, leading to the broader Mössbauer transmission spectrum. Samples were annealed in argon and air to study the effect of temperature on the structure. Annealing in argon did not improve the crystallinity while annealing in air caused a complete decomposition of the magnetite phase into hematite and pseudobrookite. Traces of radioactive elements were also researched and quantities compatible with naturally occurring radionuclides of terrestrial origin ( $\mathrm{Ra}$ and $\mathrm{Th}$ ) were found. 


\section{References}

[1] Braccini, S., Pellegrinelli, O. and Krämer, K. (2013) Mössbauer, X-Ray and Magnetic Studies of Black Sand from the Italian Mediterranean Sea. World Journal of Nuclear Science and Technology, 3, 31-35. http://dx.doi.org/10.4236/wjnst.2013.33016

[2] Peev, T.M., et al. (1995) Mössbauer and X-Ray Study of Natural Magnetite Sands. Journal of Radioanalytical and Nuclear Chemistry, 190, 357-361. http://dx.doi.org/10.1007/BF02040012

[3] Cruz-Sánchez, E., et al. (2004) Study of Titanomagnetite sands from Costa Rica. Journal of Alloys and Compounds, 369, 265-268. http://dx.doi.org/10.1016/j.jallcom.2003.09.064

[4] Chapenoire, S., Braccini, S., Krämer, K., et al. Peculiar Radiopaque Foreign Body in the Upper Aero-Digestive Tract in a Newborn Corpse from the Indian Ocean. To Be Submitted to Forensic Science, Medicine, and Pathology (Unpublished).

[5] Skoog, D.A. and Leary, J.J. (1992) Principles of Instrumental Analysis. Saunders College Publishing, Orlando.

[6] Murad, E. and Cashion, J. (2004) Mössbauer Spectroscopy of Environmental Materials and Their Industrial Utilization. Kluwer Academic Publishers, Boston. http://dx.doi.org/10.1007/978-1-4419-9040-2

[7] Gilmore, G. and Hemingway, J. (1995) Practical Gamma-Ray Spectrometry. John Wiley \& Sons, Chichester.

[8] Okudera, H. (1997) Single Crystal X-Ray Studies of Cation-Deficient Magnetite. Zeitschrift für Kristallographie, 212, 458-461. http://dx.doi.org/10.1524/zkri.1997.212.6.458

[9] Shannon, R.D. (1976) Revised Effective Ionic Radii and Systematic Studies of Interatomic Distances in Halides and Chalcogenides. Acta Crystallographica Section A, 32, 751-767. http://dx.doi.org/10.1107/S0567739476001551

[10] Sawada, H. (1996) An Electron Density Residual Study of $\alpha$-Ferric Oxide. Materials Research Bulletin, 31, 141-146. http://dx.doi.org/10.1016/0025-5408(95)00183-2

[11] Grey, I.E., Li, C. and Ness, T. (1998) Nonstoichiometric Li-Pseudobrookite(ss) in the $\mathrm{Li}_{2} \mathrm{O}-\mathrm{Fe}_{2} \mathrm{O}_{3}-\mathrm{TiO}_{2}$ System. Journal of Solid State Chemistry, 141, 221-228. http://dx.doi.org/10.1006/jssc.1998.7959

[12] Guo, W.Q., Malus, S., Ryan, D.H. and Altounian, Z. (1999) Crystal Structure and Cation Distributions in the $\mathrm{FeTi}_{2} \mathrm{O}_{5}-\mathrm{Fe}_{2} \mathrm{TiO}_{5}$ Solid Solution Series. Journal of Physics: Condensed Matter, 11, 6337-6346. http://dx.doi.org/10.1088/0953-8984/11/33/304

[13] Sources of Ionizing Radiation, UNSCEAR, Report to the General Assembly, Volume I, Scientific Annexes A and B, 2008.

http://www.unscear.org/unscear/en/publications/2008_1.html 
Submit or recommend next manuscript to SCIRP and we will provide best service for you:

Accepting pre-submission inquiries through Email, Facebook, LinkedIn, Twitter, etc. A wide selection of journals (inclusive of 9 subjects, more than 200 journals)

Providing 24-hour high-quality service

User-friendly online submission system

Fair and swift peer-review system

Efficient typesetting and proofreading procedure

Display of the result of downloads and visits, as well as the number of cited articles

Maximum dissemination of your research work

Submit your manuscript at: http://papersubmission.scirp.org/ 